\title{
A representação dos curdos no melodrama turco: "Sila, prisioneira do amor"
}

\section{Pricyla Weber Imaral*}

DOI: 10.11606/issn.2318-8855.v10i1p505-536

Resumo: Este artigo retoma de maneira resumida a análise desenvolvida a respeito das representações das populações curdas nas telenovelas turcas, buscando entender o poder da mídia em influenciar a percepção de nacionalidade dos cidadãos. A pesquisa é feita através da telenovela "Sila Prisioneira do Amor". A partir da análise da telenovela foi desenvolvido um estudo a respeito da narrativa melodramática como maneira de promover estilos de vida e cultura. Neste cenário, buscamos extrair os estereótipos que corroboram para a estigmatização da população curda no país através dos meios de telecomunicação, neste caso, o melodrama turco "Sila, prisioneira do amor". Alicerçamo-nos, então, na fonte ficcional para expor como os processos de silenciamento histórico estão implícitos na trama e trazem uma reflexão sobre o que seria uma cultura "atrasada". Neste aspecto entendemos o uso do melodrama como um auxiliar pedagógico que atua na educação do ethos nacional, e a televisão como uma ferramenta que auxilia no processo de modernização do país.

Palavras-chaves: Curdo; Curdistão; Nacionalismo Turco; Telenovela; Turquia.

* Bacharela em História Memória e Imagem, título adquirido pela Universidade Federal do Paraná. Possui experiência em pesquisa na área de história contemporânea e mundo pós-colonial no Oriente Médio. As principais pesquisas desenvolvidas pela autora estão relacionadas aos processos de partição do Oriente Médio no pós-guerra, processos de assimilações culturais tais como: turquificação, arabização e persianificação. Trabalhou principalmente com as populações curdas na Síria e Turquia e seus projetos de emancipação. Desenvolveu estudos de Mídias melodramáticas turcas e a representação da população curda na televisão. 


\section{artigos}

\section{Pricyla Weber Imaral}

\section{Introdução}

Sila (Cansu Dere) é uma jovem que quando pequena foi vendida pelo pai (curdo) à uma rica família de Istambul (turca), para que seus pais pudessem pagar o tratamento de saúde de seu irmão mais velho Azat (Cemal Toktaş). Sila cresce em Istambul usufruindo da "modernidade" presente na cidade. Mais tarde, seu pai biológico, Celil (Menderes Samancılar) reaparece, sob o pretexto de que sua mãe biológica estava muito doente e desejava vê-la uma última vez. Sila, então, concorda em voltar a sua terra natal e conhecer seus familiares. No entanto, o verdadeiro motivo de Celil levá-la de volta à Mardin ${ }^{1}$ é para que a jovem se case em uma cerimônia de troca de esposa conhecida como Berdel, ${ }^{2}$ a fim de pagar uma dívida de sangue que seu irmão Azat adquiriu com a principal família da região, ao fugir e desonrar Narin (Boncuk Yılmaz), a caçula da família Genko. ${ }^{3}$ A região onde a novela se passa fica no sudeste da Turquia, entre as cidades de Mardin, Midyat e Diyarbakir. Segundo a trama, esta região possui organizações políticas tribais, configurando-se através do sistema de clãs, no qual as autoridades permanecem sob a figura de um agha. ${ }^{4} \mathrm{O}$ drama, portanto, tem como enredo principal a vida de Sila após o casamento forçado com Boran (Mehmet Akig Alakurf).

A análise central da telenovela pautar-se-á na representação dos curdos em meios midiáticos turcos, tendo em vista a construção de identidades antagônicas.

\footnotetext{
${ }^{1}$ Mardin fica na região sudeste da Turquia, faz parte da região de Bakur, Curdistão Turco. A região está localizada próximo à fronteira com a Síria.

${ }^{2}$ Berdel é uma cerimônia de troca de esposas, esta tradição serve para evitar conflitos ou mortes, muitas das vezes a "desonra" (mulher noiva, ou solteira que fugiu com um homem que não era seu noivo), é paga com quantias em dinheiro, carros, casas, até armas, em última instância, outra mulher da família da noiva e dada à família que se sentiu desonrada a fim de que a dívida seja paga (KARDAM, Filiz: 2005).

${ }^{3}$ Clã Genko - família de aghas que governam a região.

${ }^{4}$ Chefe de uma tribo ou clã.
} 


\section{artigos}

A representação dos curdos no melodrama turco "Sila: prisioneira do amor" Nesse sentido, é relevante estudar a construção de alguns personagens na trama. No caso, os pais biológicos de Sila, Celil e Bedar (Zeynep Eronat). Eles são importantes para essa análise, a medida em que se constrói um estereótipo muito tipificado de como seriam os Curdos na região de Mardin. De forma muito sucinta, os personagens são apresentados como camponeses miseráveis, incultos, iletrados cuja maior missão de suas vidas é manter as tradições. Desta maneira, tentam explorar a imagem de uma região que, segundo a ótica ocidentalista, estaria "atrasada" em relação ao resto da Turquia, travando assim, um embate maniqueísta entre modernidade e tradição. Esses ícones são apontados de forma dual travando um conflito de narrativa, entre Mardin versus Istambul, laicidade versus religião, turcos versus curdos, e assim por diante.

A telenovela parte do pressuposto de que as minorias são aceitas e convivem de forma harmoniosa dentro do Estado. Contudo, conforme veremos mais à frente, esta relação é problemática e bastante conflituosa, visto que existe longo histórico de perseguição ao grupo desde a época da formação da República da Turquia. É sobre esta base que nos aproximamos à produção televisiva selecionada para, a partir daí, questionar os processos de formação de identidades políticas sobre uma narrativa melodramática, assim como as particularidades do imaginário moderno na Turquia e o papel dos seus outros constitutivos, particularmente nesta narrativa. a população curda. O discurso anti-curdo endossado pelos meios de comunicações reforça estereótipos de violência e terrorismo que são essenciais para a legitimação de um estado de exceção e ocupação da Turquia em território Sírio.

\section{TURQUIA ENTRE MODERNIDADE E TRADIÇÃO}

Existe na Turquia uma disputa de narrativas que se estende desde o início da 


\section{artigos}

\section{Pricyla Weber Imaral}

era Kemalista ${ }^{5}$. Durante o processo de modernização e seu alinhamento com a Europa, a Turquia passou a imaginar uma nova nação que contivesse uma identidade "europeizada". Esta, no entanto, foi produzida através de supressão de vários grupos. Ao analisar o desmantelamento do Império Otomano e a criação da República da Turquia, nos deparamos com o seguinte problema: a ambiguidade produzida através do discurso romantizado da produção nacional, que por um lado exaltava um passado "glorioso" e por outro, tentou apagar os "orientalness" e construir o nacionalismo voltado para "opan-turkishism" na tentativa de resgatar uma turquidade presente em culturas antigas dos sumérios e hititas que haviam habitado a região da Anatólia (DEVÉS-VALDÉS, 2014, p.658). Ou seja, ao mesmo tempo em que combatia o "atraso" oriental, fazia uso do mesmo para legitimar a construção da nova identidade do país.

Para Eric Hobsbawm, existem basicamente dois tipos de tradições; uma é a tradição inventada, utilizada para fins políticos, construída e formalmente institucionalizada. Existem também as tradições que remetem algum momento no passado, mas que não é possível localizá-lo temporalmente (HOBSBAWM, 2014: p.7). O autor alega que a invenção das tradições é essencialmente um processo de formalização e ritualização, caracterizado por referir-se ao passado, mesmo que seja apenas pela imposição da repetição (lbid, p. 11).

Nesta perspectiva, as tradições combatidas por Atatürk são as de criações mais

\footnotetext{
${ }^{5} \mathrm{O}$ período entendido como kemalista se configurou a partir de declínio e queda do Império Otomano, se consolidou com a criação do moderno Estado Turco. Tem esse nome por fazer referência ao criador do Estado Mustafá Kemal Atatürk, que desenvolveu uma "revolução francificada", alinhando os projetos nacionalistas para o mundo ocidental. Nesse período, Atatürk desenvolveu seu projeto baseado em aspectos como: populismo; supressão do califado frente a secularização; homogeneização do território; e mudanças no campo da economia, passando de colonial para nacional. Cabe ressaltar que o projeto kemalista é ultranacionalista, seu projeto de construção de um Estado homogêneo suprimiu minorias étnicas como os curdos e armênios.
} 


\section{artigos}

A representação dos curdos no melodrama turco "Sila: prisioneira do amor" fluidas que não existe um recorte temporal específico em detrimento das tradições inventadas, pois, estas servem para legitimar a criação e consolidação da nação. Visando a substituição da velha tradição "tribal" ou religiosa à tradição inventada, que é carregada de símbolos nacionalistas, como: bandeiras, hino nacional, entre outros. É justamente sobre esta tradição inventada que muitos curdos surgem como "problema", à medida em que passam a recusar a Nação turca. Para além da laicização como um problema de combate às tradições, é preciso analisar com cautela o caso específico do enfrentamento às tradições curdas e como ela foi se consolidando ao longo dos anos a partir da não submissão da população curda ao Estado.

O conflito que surge a partir deste embate de narrativas se dá justamente a partir da aplicação da tradição inventada. As tradições curdas, por exemplo, mantiveram focos de resistência fazendo com que permaneçam até os dias atuais, como é o caso das organizações tribais de clãs, o qual existe a figura política do agha e de todo um aparato que não necessariamente está ligado ao Estado. E, mais atualmente, temos a proposta do Confederalismo Democrático em curso no Curdistão Sírio, como uma autogestão que também não recorre ao Estado. Ou seja, temos duas propostas que não são condizentes com a narrativa do Estado turco.

A dificuldade em aceitar as tradições novas criadas pelo imaginário nacional, não se deu única e exclusivamente pelas populações curdas. Hobsbawm ressalta que as tradições criadas no século XVIII e XIX ocupavam um espaço muito pequeno na vida cotidiana e autônoma da maioria das pessoas, em detrimento à pequenos grupos de subculturas presentes nas sociedades agrárias, por exemplo (HOBSBAWM, 2014: p.19). Ou seja, as tradições combatidas pelo Estado continuavam sendo mais fortes que as inventadas. Nesse sentido, pode-se alegar que o nacionalismo turco não 
Pricyla Weber Imaral

teve grandes efeitos sobre as populações em Bakur (Curdistão turco). Motivo pelos quais diversos conflitos se deram a partir da não adequação dos curdos ao sistema burocrático de Estado.

\section{O CONTEXTO DA TELENOVELA}

"Sila, prisioneira do amor" se insere na discussão conflituosa entre turcos e curdos justamente por se tratar de uma produção televisiva que pretende expor a região de Mardin. Esta exposição, entretanto, consiste em construções de um imaginário coletivo que entende os curdos como portadores de uma tradição retrógrada que se opõe ao estilo de vida da "moderna" e urbana Turquia. Para compreender melhor a narrativa, é preciso atentar-se principalmente à palavra tradição e seu emprego durante toda a trama, pois, esta, baseia-se em conceito chave para se pensar a nação turca em contraste com as populações curdas. Nesse sentido, a telenovela retrata as tradições curdas como violentas, apelando principalmente para as questões que envolvem Blood feud e crimes de honra. ${ }^{7}$

A telenovela tratará alguns aspectos destes crimes, como o processo de troca de esposas chamado de berdel, e os conflitos por distribuição de terras e água, representados pelas lutas entre clãs vizinhos e consequentes mortes de seus atores. A narrativa busca sobremaneira desqualificar a formação tribal e cultural curda,

\footnotetext{
${ }^{6} \mathrm{~A}$ área reivindicada como Curdistão está localizada próximo à cordilheira dos Zagros e Taurus contemplando Turquia, Síria, Irã e Iraque. Onde, Başûrê (Curdistão iraquiano), Bakur (Curdistão turco), Rojava (Curdistão sírio) e Rojhilat (Curdistão iraniano), sendo a Turquia o país que concentra maior número de curdos na região, cerca de 20 milhões vivem na Turquia, chegando a $25 \%$ da população. Kurde Institut: <https://www.institutkurde.org/en/info/the-kurdish-population-1232551004> Acesso em: 06/04/2019.

${ }^{7}$ Conflitos de sangue, geralmente travado por duas famílias, ocasionalmente acontecem mortes por armas de fogo, geralmente os conflitos tratados são por causa de problemas referentes à distribuição de água, terra, ou crimes de honra, geralmente estes conflitos duram anos, e seguem algumas gerações da família, tribo ou clã (içLí, 1994, p, 69).
} 


\title{
artigos
}

\section{A representação dos curdos no melodrama turco "Sila: prisioneira do amor"}

fazendo-se valer do discurso modernizante perpetrado por Mustafá Kemal Atatürk ${ }^{8}$ durante a formação da República Turca, de maneira a exemplificar esta dualidade entre a modernidade das leis da Turquia e o "atraso" das leis clânicas curdas.

Ao longo da telenovela se constrói uma ideia de que os curdos vivem, morrem e matam para manter suas tradições. Contudo, é preciso olhar com bastante cautela para este aspecto, visto que, o próprio $\mathrm{PKK}^{9}$ também se contrapõe aos poderes "feudais"10 dos aghas. A trama sugere que o sistema político curdo deva ser extinto por não combinar com a sociedade turca e propõe a perpetuação do processo de apagamento histórico e cultural iniciado pelo processo de turquificação ${ }^{11}$ ainda no início do século XX. Desta forma, busca-se reforçar a necessidade de extinção do sistema de clãs, para que a nação turca seja livre do "retrocesso" e de todas as suas amarras que porventura sejam associadas ao Oriente.

\section{SILA (PRISIONEIRA DO AMOR) E O PROJETO CIVILIZADOR}

Este trabalho expõe os ícones que compõem a narrativa a fim de que a

\begin{abstract}
${ }^{8}$ Mustafá Kemal, foi o primeiro presidente da Turquia. Nesse período, Atatürk desenvolveu seu projeto baseado em aspectos como: populismo; supressão do califado frente a secularização; homogeneização do território; e mudanças no campo da economia, passando de colonial para nacional. Posteriormente ganhou o epíteto de "Atatürk", "pai dos turcos" considerado como herói nacional.

9 Partido dos Trabalhadores do Curdistão. Partido de maior influência sobre os curdos na Síria e Turquia.

${ }^{10} \mathrm{Ao}$ se tratar do sistema tribal curdo torna-se inevitável defrontar-se com o constante emprego da palavra "feudal" utilizados por diversos autores. Embora seja bastante delicado a utilização do termo, visto que se refere a um recorte territorial e temporal eurocêntrico. Utilizaremos mesmo assim, na falta de uma adjetivação melhor para explicar as relações sociais presentes dentro das organizações políticas curdas. Para Martin Van Bruinessem (1992), a utilização do termo está relacionada à forma como os grupos estão organizados dentro da lógica política e econômica, essas relações de dominação seriam quase feudais. Onde camponeses vivem em uma relação de subserviência a um agha.

${ }^{11} \mathrm{O}$ processo de turquificação foi marcado por políticas assimilacionistas de forte cunho nacionalista, visando imposição cultural. Atuando também como parte de um processo civilizatório muito maior. Por conseguinte, o país passou a combater todo e qualquer indivíduo que representasse o "atraso" promovendo a criação de uma nação turca homogênea.
\end{abstract}




\section{artigos}

\section{Pricyla Weber Imaral}

construção do imaginário social' ${ }^{12}$ a respeito das populações curdas seja, efetivamente, demonstrada na trama. Nas primeiras cenas do capítulo inicial da telenovela, já se apresenta um crime de honra. Narin, irmã de Boran Genko, o agha (líder político), foge com Azat (filho de camponeses). Boran surge armado com seus capangas montados em cavalos, a fim de encontrar o casal fugitivo para que a tradição seja cumprida, ou seja, eles sejam assassinados. Entretanto, Boran liberta o casal e decide em reunião do clã que prefere resolver a situação sem o derramamento de sangue, ou seja, uma perspectiva de inovação cultural. Esta atitude, faz parte da constituição da sua personagem, o "mocinho" que vive uma guerra interna entre cumprir as tradições ao mesmo tempo em que luta contra elas.

Durante a reunião do clã, Boran sai em defesa de sua irmã, porém, seu tio alega: “Meu filho, uma mulher de nossa família foi raptada, não podemos ficar aqui sentados como se fosse uma celebração, existem as tradições. Você decide! Só existem duas opções, ou você se casa com a irmã de Azat, ou, caso contrário, você não poderá controlar o clã". O pai de Boran reforça: "Não é fácil, controlar vinte mil pessoas. Quando lhe dei a posição de agha, você sabia que não seria fácil, pode ser que você tenha que matar a sua mãe, se a tradição assim mandar [...] é assim por séculos, e não será mudado"13. Frente à pressão desempenhada pelo clã, Boran demonstra insatisfação diante da impossibilidade de não poder resolver o conflito sem que a tradição seja aplicada, nesse caso, ele opta pela realização do Berdel, e decide entregar sua irmã à Azat e em troca, tomará Sila, irmã de Azat, como esposa.

\footnotetext{
${ }^{12} \mathrm{O}$ conceito utilizado nessa pesquisa, está ancorado no filósofo Cornelius Castoriadis. No qual o autor entende que Imaginário social é a tentativa de explicar as diferenças presentes entre diferentes sociedades. Esse imaginário segundo o autor, estão presentes em normas, valores, linguagens etc. 0 autor entende que esse processo de criação do imaginário social é essencialmente imaginário e não racionais. Em outras palavras "a sociedade é uma criação, uma autocriação" (CASTORIADIS, 1997. P.5). A sociedade imagina a si mesmo, assim como imagina o "outro".

${ }^{13}$ SILA, PRISIONEIRA DO AMOR, 2016: (Brasil), capítulo 1.
} 


\section{artigos}

A representação dos curdos no melodrama turco "Sila: prisioneira do amor"

Estes primeiros eventos apresentados, demonstram a construção do estereótipo curdo como violento. Os personagens firus e Zinar agha, respectivamente pai e tio de Boran, representam a rigidez do sistema clânico. Estes personagens são importantes dentro da trama, pois além de serem membros do clã Genko, fazem parte do conselho de patriarcas, que juntos tomam as decisões a respeito da aldeia. Nota-se de antemão, que a principal ferramenta narrativa utilizada na telenovela será a apresentação dos curdos como grupo agressivo e sanguinário. Dessa maneira, a telenovela atua como ferramenta em que se promove uma realidade que contribui para a imaginação do outro. Esta leitura é reforçada pelos diálogos dos personagens, que estão geralmente atreladas a juízos de valor sobre suas práticas culturais, através de falas como: “Talvez você precise matar sua mãe, se assim mandar a tradição"14, "As pessoas estão morrendo por causa dessa tradição estúpida"15. Estas falas retratam bem o tom que a telenovela busca empregar sobre a forma que os curdos vivem. Frases como estas sempre estão inseridas em um contexto de estupro, morte, rapto e violência doméstica, criando assim, uma associação entre as tradições curdas à violência. Quando temas como estes são expostos nos meios midiáticos, evidenciam que o estilo de vida do sudeste da Turquia deve ser combatido, pois remeteriam à barbárie. Entretanto, a situação torna-se ainda mais delicada ao passo que estas ligações na telenovela reforçam o imaginário social que o grupo étnico carrega através da estigmatização da violência e sua forçada relação com terrorismo.

O principal tema abordado pela trama são os chamados Blood feud, que contribui igualmente para este estigma enfrentado pelo grupo. Os conflitos de sangue seriam, em suma, os meios pelos quais os problemas entre clãs são resolvidos.

\footnotetext{
14 Ibid, capítulo 1.

15 Ibid, capítulo 18.
} 


\section{artigos}

\section{Pricyla Weber Imaral}

Segundo a socióloga Tülin Günşen İçli, estas práticas configuram-se como funcional no sentido de fortalecer os laços familiares ao passo que aumentam a solidariedade entre os membros da família (IÇLi, 1994). A situação de Narin e Azat qualifica-se como rapto, portanto, segundo a tradição tribal, isto seria uma desonra à família da mulher raptada, a solução então a ser tomada seria o assassinato do casal ou aplicação da tradição denominada berdel.

Como parte da prerrogativa estabelecida através das tradições, Boran precisa se casar com alguma moça solteira da família de Azat, para finalização do contrato entre as duas famílias, cansando-se com Sila. Visto que Sila casara forçada e, portanto, não teria interesse em consumar o casamento, Boran é orientado por seus pais a violentá-la para que o casamento seja validado e o contrato feito através do berdel seja mantido. Contudo, ele não o faz. Boran faz um corte em sua mão e suja o lençol de sangue, para que este seja exposto e apresentando ao clã a fim de legitimar o casamento. Sila fica desesperada e tenta fugir de várias maneiras, porém é capturada. Com o passar dos dias, ela aceita que ficará presa neste casamento para sempre. Sila, então, começa a observar que Boran é "diferente" dos líderes tribais, pois demonstra ser intelectual e aparenta ter compaixão com as pessoas comuns da aldeia, assim como demonstra ser piedoso com os animais, apaixonando-se por ele. Nesta lógica, o personagem de Boran serviria para quebrar os estereótipos sobre a suposta selvageria curda, representando a moral inovadora da história. Contudo, é apresentando justamente o contrário, pois, dentro da trama, Boran seria a exceção, ou seja, novamente a narrativa sugere que todos os curdos são violentos e incompassivos fazendo com que o comportamento de Boran seja uma raridade na telenovela.

Boran e Sila formam opostos, numa dualidade sugerida entre modernidade e 


\section{artigos}

\section{A representação dos curdos no melodrama turco "Sila: prisioneira do amor"}

tradição dando sentido e significados a partir de signos constituintes da narrativa. Neste sentido, pode-se apontar a personagem Sila, como a metáfora modernizante. Em sua primeira aparição na trama, ela surge com um biquíni tomando banho de piscina em sua mansão (cabe ressaltar que a Turquia é um país de população majoritariamente muçulmana conservadora). A narrativa evidencia o contraste pretendido através do choque cultural entre Istambul e Mardin. Boran constitui o lado tradicional, principalmente por seu cargo político de agha, o aplicador das leis tribais e o agente que simboliza a personificação da tradição curda.

Conforme mencionamos anteriormente, a palavra tradição é de suma importância para compreensão da narrativa, dando a ela um peso quando ultrapassa as fronteiras de Mardin, e espalha-se nas cidades grandes. Nessa lógica, a tradição é entendida como subversiva, ela estaria ameaçando o estilo de vida da cidade, posto que a todo momento a narrativa busca evidenciar que esta seria a única lei que o grupo obedeceria. Falas como: "O poder do clã está em suas tradições"16; "A tradição é lei e deve ser aplicada a todos"17, demonstram isso. A importância das tradições é corroborada também pela trilha sonora "Töre" (tradição), a principal música da telenovela, que tocou em todos os momentos de tensão, conflitos e até durante a morte de alguns personagens.

[...] Não é algo que venha de Deus, é a criação das pessoas. Não é algo que venha de Deus. Como podem os bebês nascerem com armas? Tradições, Tradições, Tradições... Como podem os servos de Deus se transformarem em servos das pessoas? Você colocou rancor em um cego coração. Como isto pode ser justiça? (AKSU, Sezen. Tradução nossa). ${ }^{18}$

\footnotetext{
${ }^{16}$ SILA, PRISIONEIRA DO AMOR, 2016: (Brasil), capítulo 9.

17 Ibid, capítulo 6.

${ }^{18}$ No Original turco foi traduzido para o inglês: Customs, customs, customs (how) can the servants of God become servants of people? You placed grudge into the blind heart. How can this do justice? Disponível em: <https://lyricstranslate.com/tr/Toere-Toere.html>. Acesso em: 19/02/2020.
} 


\section{artigos}

\section{Pricyla Weber Imaral}

Para Heloisa Buarque de Almeida (2001), a música é de grande importância dentro das produções melodramáticas, pois ajuda a construir personagens e cenas, usada como auxiliar da própria narrativa. A letra sugestiva transfere um juízo de valor sobre as tradições, ao passo que apresenta também o estreito laço da laicidade no país. O juízo empregado possui caráter religioso, configurando, assim, um pensamento que simboliza o afastamento dos curdos do islã em prol de suas próprias tradições "criadas pelas pessoas". Sendo assim, reforça a ideia da quebra da adstrição sunita que curdos e turcos possuíam na época do Império Otomano ${ }^{19}$. É importante notar que a forma como os curdos interpretam as leis clânicas e as aplicam está sendo exposta através de um ponto de vista turco, a fim de vender uma imagem do grupo, que em determinados momentos pode ser exagerada.

A segunda parte da trama, que se passa em Istambul, também deixa alguns signos para serem analisados. O primeiro caso é a situação de Celil, pai de Sila e Azat. Após a fuga dos filhos, Celil é obrigado a cumprir as ordens desempenhadas pelo clã, que envolveria matar os filhos. Em Istambul, Celil não consegue matar os filhos e Sila o acolhe em sua casa. Ou seja, ele tem uma atitude diferente da esperada pelo clã e pela própria trama, que passa a retratá-lo como mais uma vítima do sistema, cuja saída está na segurança trazida pela fortuna de Sila em Istambul. Celil é retratado de duas maneiras durante a trama. Inicialmente, ele é exibido como oportunista. Pois, quando teve a oportunidade de buscar sua filha ainda na infância em Istambul, ele preferiu aceitar uma grande quantia em dinheiro que o possibilitou a compra de sua casa, além de receber porções mensais em dinheiro do pai adotivo de Sila, para que ele não mais buscasse a filha. Em outro momento este estereótipo é reforçado, quando os pais adotivos de Sila morrem e deixam para ela toda a fortuna, mansões e

\footnotetext{
${ }^{19} \mathrm{Abdullah}$ Öcalan defende que os curdos experimentaram uma relativa paz, baseado na adstrição sunita que turcos e curdos possuíam durante o período otomano.
} 


\section{artigos}

A representação dos curdos no melodrama turco "Sila: prisioneira do amor" demais bens, então, Azat e Celil conspiram sobre como gastar a fortuna de Sila.

Em um segundo momento, Celil é retratado como um sujeito ingênuo, pois muitas pessoas conseguem passá-lo para trás, roubá-lo e aproveitar-se dele, sendo também retratado como camponês caipira. Esta proposta dos personagens, embora subjetiva, demonstra alguns aspectos importantes sobre a maneira que os curdos são entendidos, sendo retratados como camponeses famintos, dispostos a fazer qualquer coisa para sua sobrevivência, como por exemplo, vender a filha.

Após Sila conseguir fugir e refugiar-se em Istambul, Boran e os membros do clã vão até a cidade para "caçá-la" por ter desonrado a família ao fugir. Na cidade, a família de Sila e o próprio Boran enfrentam alguns estigmas sociais, sendo sempre tratados como incivilizados. Estas atitudes tornam-se nítidas através de algumas falas, como quando uma funcionária da empresa de Boran em Istambul diz: “Não me leve a mal, mas o senhor parece diferente de alguém que cresceu em Mardin [...] Você é culto e civilizado". Boran, ofendido, a acusa de preconceito. O fato de Boran ser culto parece não combinar com os outros líderes políticos da região. E de fato, a questão de já ter passado por educação formal traz um peso ao personagem fazendo com que ele se torne um "quase civilizado" na narrativa binária da trama, visto que muitas vezes ele se posiciona contra as tradições.

Não apenas Boran passa por constrangimentos como estes na cidade, mas também o pai de Sila e seu irmão caçula, Emir. Este, tem seu sotaque questionado algumas vezes durante a trama, sendo constantemente satirizado pelos colegas na escola. Os curdos não falam turco essencialmente, eles foram forçados à uma alfabetização turca, visto que por muitos anos foi proibido falar qualquer outro idioma que não o oficial. Sobre isso, as autoras Sezgin e Wall (2005) sugerem que os 


\section{artigos}

\section{Pricyla Weber Imaral}

curdos são interpretados na sociedade turca como ignorantes e uma das razões disso está associada ao fato de não conseguirem falar turco com fluência.

A terceira e última parte da telenovela busca retratar o retorno dos personagens de Istambul à Mardin. Nesta etapa, Sila tem a sentença de morte adiada pelo clã, após anunciar sua gravidez - fruto de um estupro de Boran. Narin e Azat também têm a sentença adiada, contudo, Azat é assassinado por um dos primos de Boran, fato que acaba libertando Narin do contrato Berdel. Nesta fase, Sila retorna mais empoderada, passando de uma postura de mocinha injustiçada a uma mulher forte que começa a lutar ativamente contra as tradições. Nesse sentido, a personagem atinge o estereótipo esperado dentro da produção melodramática - visto que ela corresponde a todos os aspectos esperados para gerar empatia no público a respeito do que se espera de uma protagonista. Jovem, virginal, vendida na infância, depois obrigada a se casar, enfrentou violência física, psicológica e sexual. Mas, superou tudo, passando de vítima a uma importante mulher de negócios bemsucedida.

Esta era uma convenção narrativa: a heroína que começa pobre, virgem e desamparada e no processo de ascensão social deveria sofrer transformações muito fortes, como mudar sua roupa, seu penteado sua forma de falar. [...] É esperado que a personagem passe por uma transformação, passando de uma heroína pobre em mulher rica, bonita e poderosa (ALMEIDA, 2001: p.207).

Como parte desta problemática, Sila, assumindo outra postura, começa a atuar contra o clã de forma mais incisiva, contando com ajuda inclusive de Boran. O agha inicia a construção de uma escola primária que receberá o nome de Sila. Ao mesmo tempo, ela inaugura uma fábrica na região, onde emprega camponeses pobres, cujos filhos devem permanecer na escola para garantirem o emprego. Este momento torna-se importante para entender Sila como elo modernizante em Mardin, sua estadia e mudança de paradigma de "mocinha" para heroína a torna a pessoa capaz 


\section{artigos}

A representação dos curdos no melodrama turco "Sila: prisioneira do amor" de promover um questionamento na sociedade local. Contudo, como sabe-se, por mais que Sila também seja curda, ela cresceu em Istambul, portanto, teria sido assimilada pela modernidade turca e possuiria o "fardo" de levá-la a Mardin.

O comportamento do casal desagrada o clã, por estarem mudando as estruturas sociais de vilarejo, fazendo com que a liderança política de Boran seja questionada, até que, por fim, o conselho dos patriarcas resolve retirá-lo do cargo. Seu tio Zinar então assume a liderança do clã, prometendo pulso firme com o cumprimento das tradições, dividindo os apoiadores da família Genko em grupos que apoiavam as tradições e grupos que lutavam contra elas. Ao longo de toda a trama procurou-se mostrar que a educação formal seria a solução para resolver os problemas culturais do grupo, ao passo que vê na educação uma saída para este "atraso". Este raciocínio se dá através das falas de Sila: "A escola é para orientar as pessoas a ignorar a tradição $20 "$; "A gente sabe que a educação é capaz de mudar o mundo Narin ${ }^{21 "}$. A protagonista, portanto, seria o ícone constituinte que dá vida ao processo civilizacional, procurando sempre criticar a cultura local: "Prefiro que meu filho morra, do que se torne um homem ruim, como manda a tradição 22"; "Não sei se estarei viva para ver meu filho lendo um livro ${ }^{23 \prime}$, constituindo, assim, um debate antagônico no qual existe apenas uma saída. Esta abordagem também traz a possibilidade de interpretação de que apenas alguém de fora (Istambul) poderia fazer o papel da reflexão cultural e questionamento das tradições. É ignorado, por exemplo, o próprio PKK, que se opõe aos poderes "feudais" dos aghas, mas esta crítica não consiste na morte ou no apagamento cultural, conforme sugerido pela

\footnotetext{
20 SILA, PRISIONEIRA DO AMOR, 2016: (Brasil), capítulo 96

${ }^{21} \mathrm{Ibid}$, capítulo 190.

22 Ibid, capítulo 68.

${ }^{23}$ Ibid, capítulo 61.
} 


\section{artigos}

\section{Pricyla Weber Imaral}

trama ${ }^{24}$.

Caminhando para o final da narrativa, no penúltimo capítulo, Sila cumpre seu papel de heroína, ao passo que seu posicionamento e sua influência sobre Boran conseguem, por fim, mudar a mentalidade local. O papel de Sila dentro da trama representou uma ponte que buscou a transição da "atrasada" Mardin, devido às tradições, até o desenvolvimento, investindo em empresas, fábricas, educação etc.

A modernidade trazida por Sila teve um efeito dentro do clã e em toda a aldeia, conforme o desfecho do último capítulo. Quando Zinar agha devolve seu título a Boran, por entender que ele seria um líder mais justo e coerente para o clã, Boran então aceita o cargo e convoca todo o conselho de clãs, aldeões e patriarcas, para fazer um pronunciamento. Neste evento, Boran fala das escolas e da importância delas para a evolução do mundo e da região. Esta fala remete diretamente à Sila visto que sua personagem serviu como impulso para a perpetuação das escolas como parte de um projeto civilizador e colonizador. Em seu discurso, Boran se emociona ao anunciar as novas mudanças:

\footnotetext{
"Há milhares de anos construíram aqui a maior civilização do mundo, e faremos isso novamente. [...] Olhando daqui eu posso ver o sofrimento que cada um de vocês passou. O nosso povo já passou por tantos tempos difíceis, que eu começo a ver a figura de um agha de uma forma um pouco diferente. Será que um agha é realmente necessário nesse mundo? [...] minha decisão final é que o cargo de agha será abolido. Assim, seremos um exemplo para os outros clãs. [...] Quando eu fui escolhido para ser líder de vocês pela primeira vez, meu pai me disse que um agha tem que ser justo, forte e não poderia voltar atrás das suas decisões. Se vocês obedecerem a isso, poderão resolver seus próprios problemas com ajuda da lei e nos tribunais. Vocês conseguem, eu realmente acredito em vocês [...] vamos construir uma nova ordem juntos que será baseada na confiança e no respeito."25
}

\footnotetext{
${ }^{24}$ ROJAVA NO ESTA SOLA, Publicação anarquista solidaria com la lucha del pueblo curdo. №2 p.16.

${ }^{25}$ SILA, PRISIONEIRA DO AMOR, 2016: (Brasil), capítulo 199.
} 


\section{artigos}

A representação dos curdos no melodrama turco "Sila: prisioneira do amor"

Quando Boran decide por definitivo abolir o cargo de agha, ele por si mesmo está representando a conclusão do projeto civilizador. Ao tomar esta iniciativa, demonstra que sua assimilação ao estilo de vida turco foi concluída com sucesso. Este ponto pode ser justificado pelos argumentos defendidos por ele: "Usem as leis e tribunais para resolver seus problemas". Todo este aparato burocrático é parte do projeto estatal ao qual Boran passou a se submeter, abandonando seus costumes "rebeldes" em prol de um bem maior: a civilização. A submissão de Boran às burocracias oferecidas pelo Estado é de grande significado. Nesta ótica, Abdullah Öcalan ${ }^{26}$, em "Confederalismo Democrático", defende que o Estado-nação e a burocracia não podem existir um sem o outro. Juntos desempenham um papel crucial para manter a estrutura política estatal.

Estado-nação precisa de instituições adicionais para proteger sua base ideológica, bem como suas estruturas jurídicas, econômicas e religiosas. A constante expansão da burocracia militar e civil custa caro e serve apenas para preservação do próprio Estado, que por sua vez coloca a burocracia acima do povo (ÖCALAN, 2008, p.20).

A defesa da burocracia estatal é, portanto, extremamente significativa para se pensar o movimento político curdo e sua luta pelo direito de autodeterminação. Ao assumir uma submissão ao Estado através da burocracia, Boran abre mão não apenas do sistema de clãs e suas tradições, mas, também de alguns aspectos culturais que representam uma grande parcela do grupo étnico.

A cena final da telenovela traz Sila e Boran de mãos dadas, caminhando lentamente até que finalmente somem no horizonte. Nesse momento, surge a narração de um homem explicando para duas crianças sobre a história de amor de Sila e Boran:

\footnotetext{
${ }^{26}$ Líder e cofundador do Partido dos Trabalhadores de Curdistão, atualmente encontra-se preso, sendo o principal ativista e político de atuação curda.
} 


\section{Pricyla Weber Imaral}

"E ninguém nunca mais viu a Sila e o Boran [...] eles lutaram muito pelo seu povo, eles acreditaram que as coisas poderiam mudar, eles lutaram contra um pensamento primitivo, contra ignorância e contra a tradição sem sentido. Eles nos mostraram um caminho para a luz. Passaram por inúmeros desafios, mas o amor lhes mostrou o caminho, Ihes deu coragem e esperança para que homens e mulheres convivam com respeito e admiração. Eles mudaram as coisas sim, mas ainda há muito a ser feito. E agora, vocês seguem de onde eles param, vocês continuam as lutas deles, lutem por amor, por respeito e pela igualdade. [...] Eles andaram de mãos dadas, contra todos os tipos de injustiças, contra mortes desnecessárias, contra desunião das pessoas que tinham que lutar juntas para melhorar o estilo de vida na mesopotâmia". ${ }^{27}$

O final da trama é simbólico quando pensamos na história contemporânea da Turquia. O processo modernizante e civilizatório implementado no país, são significativos para refletir o projeto nacional turco. A telenovela Sila, insere-se neste contexto, sendo Sila um agente ativo que leva a cabo o projeto civilizador em Mardin. Quando o narrador chama as crianças a continuarem o processo iniciado por Sila, "Agora vocês seguem de onde eles pararam", ele não apenas está falando com as crianças na cena propriamente dita, mas direciona ao público em geral à lutar contra "todos os tipos de injustiças", no sentido de lutar abertamente contra as tradições, de onde, segundo ele, viriam as injustiças e "mortes desnecessárias."

O final deste último capítulo é importante para se pensar o que a trama está tentando passar desde o início. A construção de um ideal de "outro" que a única forma de conseguir fazer parte de "nós" é através da adequação e assimilação cultural. Nesse aspecto, as produções televisivas são importantes à medida em que promovem um estilo de vida ideal. "Neste caso, a mídia influencia diretamente as atitudes e percepções das audiências, construindo uma visão de mundo que reforçaria estereótipos negativos" (ALMEIDA, 2001: p.16). Em Sila por exemplo, a ideia a ser reforçada é o quão cruel seriam as tradições curdas.

27 SILA, PRISIONEIRA DO AMOR, 2016: (Brasil), capítulo 199. 


\title{
artigos
}

A representação dos curdos no melodrama turco "Sila: prisioneira do amor"

A produção televisiva muitas vezes idealiza um estilo de vida que é incompatível com a vida camponesa. Segundo Almeida: "As telenovelas treinam o espectador numa linguagem televisual muito mais ágil e, assim, auxiliam na compreensão e interpretação dos anúncios que em poucos segundos pretendem veicular estilos de vida, atitudes e comportamentos" (ALMEIDA, 2001: p.23). Nesse sentido, focam no estilo de vida urbano das grandes cidades, produzindo um modelo ideal de nação, no caso de Sila, a Turquia. Neste ideal, imagine-se a sociedade turca rica desenvolvida no qual Mardin não consegue se encaixar, por isso, a única saída é a assimilação.

\section{PODE A TELENOVELA INFLUENCIAR NA PERCEPÇÃO DA NACIONALIDADE?}

As telenovelas promovem estilos de vida. Estes, no entanto, geralmente estão associados aos grandes centros urbanos, conforme aponta Heloísa Buarque de Almeida (2013). A autora postula que as telenovelas tendem a ensinar algumas coisas, principalmente para as populações mais pobres, de baixa escolaridade e pouco capital cultural, que entendem a televisão como fonte confiável de informação. Consoante a isso, em "Media Worlds" os autores entendem que os produtos oferecidos na televisão cooperam para promoção desta "educação" e estilo de vida pretendido:

\begin{abstract}
Maior parte do rádio e da televisão tem controle estatal ou está nas mãos de profissionais da indústria cultural que, como argumenta Stuart Hall (1980), tendem a compartilhar os "códigos dominantes" do Estado-nação. A censura antecipatória e a autocensura são as normas. Seja criando lealdade, moldando entendimentos políticos, promovendo o desenvolvimento nacional, "modernizando", promovendo o planejamento familiar, ensinando a privatização e o ethos capitalista, criando bons socialistas ou entretendo inocentemente. A mídia tem sido vista como ferramentas poderosas para hegemonia ou transformação social (GINSBURG, ABU-LUGHOD AND BRIAN LARKIN, 2002, p.11. Tradução nossa). ${ }^{28}$
\end{abstract}

\footnotetext{
${ }^{28}$ No Original: Most radio and television has been state-controlled or in the hands of culture industry
} 
Sabendo que as telenovelas têm poder de persuasão e influência sob seus telespectadores, a mídia é capaz de direcionar o público, contra ou a favor dos grupos minoritários. "Estudos anteriores da imprensa turca também demonstram que a mídia turca em geral tende a definir a nação através de ameaças internas e externas percebidas" (SEZGIN, WALL, apud Yumul e Ozkirimli, 2000. Tradução nossa). ${ }^{29}$

A telenovela legitima um sentimento nacionalista, criando uma diferenciação do que é ser turco, "moderno e civilizado", e do que é ser o outro não civilizado. Ao olharmos para os discursos nacionalistas difundidos no início do século passado, “Um país, uma língua uma bandeira"30 ${ }^{\prime 30}$ perceptível que isso ainda faz muito sentido no país, suprimindo assim os demais indivíduos. Isso também ocorre dentro da própria trama, quando a associação da população curda com a violência por si só se encarrega de criar barreiras sociais que fogem da narrativa ficcional e vão para a realidade cotidiana das pessoas. Neste aspecto, a exploração da imagem dos curdos na televisão, tem uma linguagem parecida com a reproduzida pelos jornais. Conforme apontam Dilara Sezgin e Melissa Wall (2005), a representação dos curdos nos jornais do país é discriminatória, sugerindo uma cultura não digna de respeito:

Neste estudo, a reprodução da mídia e a justificativa do governo conferem à elite dominante uma posição superior que ajuda a manter a posição desigual dos curdos na vida social turca. Por fim, os curdos são mantidos em silêncio na cobertura da mídia (a discussão é sobre eles e não com eles), são principalmente associados ao terrorismo (o PKK) e são retratados como divisores com demandas irracionais. A estrutura da cobertura é muito

professionals who, as Stuart Hall (1980) has argued, tend to share the "dominant codes" of the nationstate Censorship and anticipatory self-censorship are the norms. Whether to create loyalty, shape political understandings, foster national development, "modernize," promote family planning, teach privatization and the capitalist ethos, make good socialists, or innocuously entertain, media have been viewed as powerful tools for hegemony or social transformation.

${ }^{29}$ No original: Previous studies of the Turkish press have also found that the Turkish media in general tend to define the nation via perceived internal and external threats (Yumul and Ozkirimli, 2000).

${ }^{30}$ Slogan amplamente difundido durante a formação da República turca. 


\section{artigos}

A representação dos curdos no melodrama turco "Sila: prisioneira do amor"

nacionalista e considera os curdos como inimigos, menosprezando e desacreditando sua existência e valores culturais (SEZGIN, Dilara. WALL, Melissa A. 2005: p.795. Tradução nossa) ${ }^{31}$

As lutas discursivas promovidas pela elite turca para articular a identidade curda são muito eficientes. A manifestação nacional tão presente nas narrativas midiáticas possui papel fundamental dentro do país, chegando a articular as massas de tal modo que, aconteceram tentativas de linchamentos contra curdos e ativistas de esquerda no país (ZEYDANLIOGLU, 2008). A televisão, como provedora de cultura, adentra as casas fornecendo elementos do que seria uma "cultura pública" (ABULUGHOD, 2002), promovendo a recognição da população com a cultura "Ocidental" de Istambul, ao passo que se afasta das demais localidades interioranas. Segundo Yörük (2013), Istambul é uma dessas cidades que busca integração com redes comerciais e culturais transnacionais, preservando suas características locais específicas. A cidade teve desde de sua criação e mudança de nome um papel extremamente importante no intercâmbio comercial, político e cultural. Nesta perspectiva, podemos deduzir que existe, portanto, um ethos istambulenses que pretende ser reafirmado a partir das narrativas midiáticas.

Os autores Faye D. Ginsburg, Lila Abu-Lughod, e Brian Larkin (2002) argumentam que "a nação ainda é um quadro de referência poderoso, especialmente nos muitos países onde o Estado tem sido o principal ator na criação e regulação de redes de mídia" ${ }^{32}$. Podemos, então, apontar algumas produções televisivas como

\footnotetext{
${ }^{31}$ No original: In this study, media reproduction and justification of the government stand accords the ruling elite a dominant position and helps it maintain the unequal position of Kurds in Turkish social life. Ultimately, Kurds are kept silent in media coverage' (discussion is 'about' them not 'with' them), are mostly associated with terrorism (the PKK), and are portrayed as divisive and as putting forth unreasonable demands. The framework of the coverage is very nationalistic and regards Kurds as enemy.

${ }^{32}$ No original: The nation is still a potent frame of reference, especially in the many countries where the state has been the prime actor in the creation and regulation of media networks.
} 


\section{artigos}

\section{Pricyla Weber Imaral}

importantes fontes de difusão da narrativa oficial que é divulgada por toda mídia turca.

A representação dos curdos frente à mídia local é sempre associando-os ao terror em narrativa emocional, trazendo relatos "tristes e violentos" e gerando no público uma revolta perante o grupo; "eles têm o sangue de milhares em suas mãos" (SEZGIN, Dilara. WALL, Melissa A. 2005: p.791). Esses discursos apaixonados fazem parte da narrativa do Estado-nação em que a Turquia pretende fazer objetificação da população curda, da qual é impossível dissociar a sua imagem da violência, em outras palavras a "selvageria" do grupo ameaça a integridade do Estado.

A indústria cultural estaria a serviço do Estado ao passo que deslegitima a produção de identidades consideradas subalternas à nacional. Nesse aspecto, “cinema, vídeo e televisão - como tecnologias de objetivação e reflexão - contêm neles um duplo conjunto de possibilidades. Eles podem ser condutores para impor os valores e a linguagem da cultura dominante a povos minoritários" (GINSBURG, ABULUGHOD, LARKIN, 2002, p.51). ${ }^{33}$ Segundo Nezih Erdoğan (1998), o caráter colonialista da mídia turca impõe valores culturais à identidade nacional, ao passo que propõe o apagamento e ressignificação de outros, colocando-se como o portador ou o agente externo que define o outro como sendo autêntico ou não, nacional ou não.

É dessa maneira, dentro da narrativa nacional, que o Estado consegue ressignificar as identidades. A exibição de Sila é problemática principalmente ao papel atribuído aos clãs curdos, na prerrogativa de não-civilização frente à sociedade "moderna". Sua difusão se relaciona com o nacionalismo turco, que vê no outro um

\footnotetext{
${ }^{33}$ No Original: Film, video, and television-as technologies of objectification as well as reflectioncontain within them a double set of possibilities. They can be seductive conduits for imposing the values and language of the dominant culture on minoritized people.
} 


\section{artigos}

A representação dos curdos no melodrama turco "Sila: prisioneira do amor" problema a ser resolvido.

\section{NACIONALISMO, FRONTEIRAS E CONSTRUÇÃO DO IMAGINÁRIO NACIONAL.}

As separações dos grupos populacionais através de estatutos étnicos e de nacionalidade serviram para criar fronteiras artificiais que evidenciou conflitos. Conforme aponta Partha Chatterjee, na década de 1970, o nacionalismo tornou-se objeto de política étnica, uma das razões pelas quais as pessoas do Terceiro Mundo se mataram através de guerras civis prolongadas, ou mesmo, atos de terrorismo (CHATTERJEE, 2004: p.90). Este embate se dá, pela maneira com a qual a nação passa a ser imaginada e difundida. Segundo Eric Hobsbawm o modelo proposto extingue outras culturas:

As nações, postas como modelos naturais ou divinos de classificar os homens, com o destino político [...] inerente é um mito; o nacionalismo, às vezes toma culturas preexistentes e as transforma em nações, algumas vezes as inventas e frequentemente oblitera culturas preexistentes: Isto é uma realidade (HOBSBAWM, 1991:19).

O longo processo de modernização e ocidentalização colocou a República Turca em evidência no que tange o distanciamento de seus vizinhos Orientais, embora o país não esteja completamente na Europa, e não tenha participado dos "movimentos evolucionais da democracia moderna" (CHATTERJEE, 2004). A Turquia, ainda assim, conta com as estruturas promovidas pela cultura Ocidental, muito embora estas estruturas estejam abaladas dados os conflitos étnicos enfrentados no país. $\mathrm{Na}$ Turquia existe uma longa e ambígua disputa interna no tocante ao tema modernidade. Para compreender melhor os motivos que levam estes embates, precisamos olhar primeiramente ao projeto de nação que está sendo pensado e promovido no país. 


\section{artigos}

\section{Pricyla Weber Imaral}

O projeto nacional encabeçado por Atatürk como vimos, teve influência da Europa. Esta iniciativa esteve pautada sobre o princípio da homogeneização nacional, legitimando assimilação e aculturação. Benedict Anderson em "Comunidades imaginadas" discorreu sobre este aspecto - segundo ele, a modernidade repousaria em um "tempo homogêneo e vazio." Para Partha Chatterjee (2004), esta concepção de homogeneidade fora construída através da historiografia moderna que imagina o espaço social da modernidade sobre a homogeneidade. Chatterjee discorda de Benedict Anderson, interpretando a modernidade como "heterogênea, irregular e densa."

O processo de turquificação ainda em movimento, não conseguiu criar um espaço-temporal que consolidava a nação turca como homogênea. Pelo contrário, conforme aponta Chatterjee, a modernidade em crise, não consegue lidar com a realidade heterogênea da nação. Existe "sob o mesmo teto" modernidades outras, que não estão dentro de contexto imaginado. A instabilidade causada encontra-se justamente no fato de que a comunidade homogênea imaginada não existe. "As pessoas podem apenas imaginar-se no tempo homogêneo vazio; elas não vivem nele" (CHATTERJEE, 2004: p.73). Outras realidades convivem no espaço-temporal da nação; diferenças culturais, étnicas e religiosas. Essas diversidades de componentes percebe a nação de forma que não corresponde com o mito criador que legitima o tempo homogêneo. Por isso, para Chatterjee (2004) a homogeneidade é utópica, visto que ela tenta moldar o todo nacional dentro de uma artificialidade, que não consegue de fato corresponder às realidades paralelas ou subalternas presentes dentro do corpo nacional.

Conforme falamos acima, o Estado-nação enquanto criação moderna não conseguiu englobar todos os presentes no território. A entidade em si só é 


\section{artigos}

A representação dos curdos no melodrama turco "Sila: prisioneira do amor" problemática, visto que está baseada numa falsa ideia de "pureza étnica". Embora a maioria das pessoas tenham uma noção de pertencimento seja subnacional ou transnacional, conforme apontam os autores Faye D. Ginsburg, Lila Abu-Lughod e Larkin (2002). Esta unificação sob o seio do Estado, romantizando as relações de pertencimento da população, tende a privilegiar determinados elementos sociais em detrimento de outros. Para o geógrafo Arjun Appadurai (2006), existe uma ideia perigosa por trás da ideia de Estado-nação: a ideia de um "ethnos nacional" que se baseia no genius étnico. Ou seja, a base racional para a consolidação do Estado-nação é o racismo. A etnicidade serviu como promotora de uma legitimidade de Estado perante determinados grupos como temos visto. Uma vez que quase todas as ideias de nação e povo se baseiam em alguma ideia de singularidade ou pureza étnica e a supressão das lembranças da pluralidade, as minorias étnicas borram os limites de um povoamento nacional (APPADURAl, 2006: p.41).

Isto acontece a partir da criação de um inimigo interno, no caso os curdos. Para que esta diferenciação seja possível, é traçado um limite entre o que é "nós" e o que são "eles." Para Appadurai (2006), este limite está baseado na teoria do bode expiatório. Onde o inimigo é fundamentado a partir de estereótipos e contrastes de identidades. Ao diferenciar este outro 'estranho' se cria desumanização ou marginalização. Se torna possível o enclausuramento, monitoramento, possível morte e extermínio deste grupo (MBEMBE, 2006). O sociólogo Daniel Feierstein (2003), alega que essa ideia de "degeneração" permitirá construir a imagem de um "outro não normalizado," este outro perde seus direitos como indivíduos ao passo em que se torna um perigo para a população o que justifica seu tratamento como não humano, como "agente infeccioso". Esta política de identificação desse outro sujeito como perigoso começa com o que o Appadurai denomina de surgimento de "identidades 


\section{artigos}

\section{Pricyla Weber Imaral}

predatórias" que reivindicam a extinção de outra coletividade para garantir sua própria sobrevivência (APPADURAI, 2006: p.46). Neste aspecto, o autor ressalta que a mídia possui papel importante, ao passo em que ajuda a construir um estereótipo desse 'inimigo da nação.'

Ao analisar a forma em que o discurso midiático é produzido na Turquia e a maneira como ele direciona e aponta os curdos como "terroristas" faz parte do projeto de nação pensado para a Turquia, Appadurai alega que a associação do grupo ao terror serve apenas para criar um medo constante de que eles venham desestabilizar o Estado. O filósofo Achille Mbembe concorda neste sentido. Para ele, Estado-nação surge para criar medo e terror, fazendo uso da violência para consolidar o domínio de um determinado grupo social (MBEMBE, 2006). Sendo assim, a política em relação a esses "outros" transformados em parasitas, que não encontram um lugar na estrutura da padronização do Estado, está sendo construída em um caminho rápido e claro para o assassinato, que está passando e montando uma fase sobre a outra: marca, assedia, isola, enfraquece e finalmente extermina. (FEIERSTEIN, 2003: p.8). ${ }^{34}$

A etnicidade, portanto, serve para trazer uma separação destes indivíduos - dos que poderão circular livremente dentro do Estado, e dos que não. Tanto Achille Mbembe quanto Arjun Appadurai entendem que a construção do inimigo interno é criada de forma ficcional para justificar o estado de exceção ou uma guerra contra o terror (MBEMBE, 2006) e com isso justificar a validade do Estado. Esses "outros" são apresentados por Appadurai como um "pequeno número" - o autor explica que na

\footnotetext{
34 No original: La política hacia estos "otros" convertidos en parásitos, que no encuentran cabida en los marcos de la normalización estatal, se va construyendo en un rápido y claro recorrido hacia el asesinato, que va atravesando y montando una fase sobre otra: marca, hostiga, aísla, debilita y, finalmente, extermina.
} 


\section{artigos}

A representação dos curdos no melodrama turco "Sila: prisioneira do amor" verdade o estado de exceção seria instaurado a partir da repercussão do medo deste grupo minoritário tomar o lugar da maioria, estes sentem-se, então, ameaçados pelas possibilidades de ocupar o lugar da minoria. Em outras palavras, para o autor, a identidade predatória na verdade seria uma circunstância onde maioria e minorias poderiam trocar de lugar, ou seja, a eliminação "deles" significa a sobrevivência do "nós". Esta minoria, portanto, ofereceria na visão do ator, perigo à "pureza" do todo nacional (APPADURAI, 2006).

Ao expor a produção do inimigo interno, é impossível dissociar o crescimento da violência do Estado com a repercussão da mídia que consiste no principal formador de opinião na atualidade. Sem ele, os discursos a respeito de terrorismo e a estereotipificação do outro não teria atingido o patamar que alcançou no século XIX. Appadurai infere que o aumento das mídias - internet, noticiário, mensagens (e porque não telenovelas?) - serviu de combustível para o que ele chama da "geografia da raiva", que seriam os resultados de "temores próximos e eventos distantes" (APPADURAI, 2006: p.77).

O melodrama auxilia a narrativa nacional que diferencia o "outro". Assim sendo, a televisão atua de forma pedagógica, visto que busca ensinar o que seria o "estranho" ou o que não cabe no ethnos nacional, se aproveitando das relações ambivalentes presentes no país ao passo que forja identidades a fim de justificar uma cultura nacional, mobilizando o público através de discursos de autenticidade.

\section{CONSIDERAÇÕES FINAIS}

A representação das populações curdas é bastante controversa quando se trata dos meios hegemônicos de comunicação. Este trabalho se propôs analisar a construção do "outro" através da produção midiática e melodramática de "Sila, 


\section{artigos}

\section{Pricyla Weber Imaral}

prisioneira do amor". Esta utiliza-se dos preconceitos e caricaturas comuns a respeito de um "inimigo interno" forjado e reforçado pelos meios de telecomunicações. A partir desta pesquisa, constatamos que o processo de turquificação iniciado no início do século XX, durante a construção do Estado nacional moderno turco, ainda repousa no imaginário social de país. Os projetos assimilacionistas desempenhados pelos kemalistas, atuaram de forma colonial no Curdistão turco, impondo o idioma, cultura e, sobretudo, a soberania de um Estado homogêneo. Em "Sila" encontramos resquícios desse processo, visto que ao término da telenovela, é sugerido a extinção do sistema clânicos no curdistão, bem como sua submissão à burocracia do Estado.

A construção da ameaça interna é uma aposta narrativa desenvolvida na telenovela. Arquitetada a partir de uma construção antagônica entre o que é ser turco e civilizado e do que é ser curdo e não civilizado; do que representa a modernidade e do que representa a tradição. Pode-se notar, que a principal característica na trama foi desqualificar a cultura e organizações políticas curdas, criando um inimigo que é "atrasado", "incivilizado", "bárbaro", "violento" e "terrorista". A associação forçada dos curdos com a violência na trama não é involuntária, ela parte de estereótipos reforçados internamente que associam os curdos a miséria, violência e terrorismo, desde os anos 1980. Discutimos as produções televisivas como dispositivos de reprodução de um pensamento anti-curdo que, ao fim, serve para legitimar a perseguição contra o grupo e a imposição de um estado de exceção.

Dentro da produção televisiva é sugerido que os problemas enfrentados no curdistão turco são essencialmente de caráter tribal, dado o "atraso" do grupo frente ao resto da Turquia. Quando na realidade, a região de Mardin encontra-se à margem da história oficial da Turquia desde o século XX, conforme aponta a antropóloga Zerrin Özlem (2010). Para a autora, Mardin está a margem da Turquia não apenas em 


\section{artigos}

A representação dos curdos no melodrama turco "Sila: prisioneira do amor" sua relação às fronteiras geográfica, mas também, pelos diversos conflitos que se passaram ali como o genocídio armênio em 1915, e a chegada dos curdos, assim como os recentes conflitos militares entre o PKK e o Estado turco.

Para além do recorte da pesquisa, podemos apontar que a construção produzida não apenas pela televisão como na mídia em geral criou um ar de instabilidade que molda a opinião pública frente, por exemplo, a ocupação da Turquia nos territórios de Rojava, Afrin e Kobane, na Síria (2018-2019). O medo do inimigo interno torna-se também uma alavancagem que justifica a exterminação deste 'pequeno grupo.' O medo da possibilidade da criação de um Estado Curdo que significaria a perda territorial da Turquia, é uma constante dentro do cenário interno.

\section{REFERÊNCIAS}

SILA, PRISIONEIRA DO AMOR, 2016: (Brasil)

FONDATION INSTITUT KURDE DE PARIS: https://www.institutkurde.org/

ALMEIDA, Heloísa. "Muito mais coisas": Telenovela, consumo e gênero. (Tese de Doutorado). Campinas - SP: Departamento de Antropologia do Instituto de Filosofia e Ciências Humanas da Universidade de Campinas, 2001.

Consumidoras e heroínas: gênero na telenovela. Estudos Feministas. Florianópolis. Vol. 15 280, p. 177-192, 2007.

. Classe média para a indústria cultural. Psicologia USP. São Paulo. Vol. 26, p. $27-36,2015$

ABU-LUGHOD, Lila. Dramas of Nationhood, The politics of Television in Egypt. Chicago:The University of Chicago Press, 2005.

ANDERSON, Benedict. Comunidades Imaginadas: Reflexões sobre a origem e a difusão do nacionalismo. São Paulo: Editora Schwarcz, 2008. 
Pricyla Weber Imaral

APPADURAI, Arjun. 0 medo do pequeno número: Ensaio sobre a geografia da raiva. São Paulo: Iluminuras, 2009.

ARCOS, Javier C.“El Kemalismo: Un caso de centralitarismo práctico-radical en la disyuntiva identitaria turca. Mustafá Kemal Atatürk (1881-1938)" USACH, Santiago, p. 83-100, 2011.

BINER, Zerrin. Ö. Acts of Defacement, Memory of Loss Ghostly Effects of the "Armenian Crisis" in Mardin, Southeastern Turkey. History \& Memory. Vol. 22, p. 6894, 2010.

CASTORIADIS, Cornelius. EI Imaginario Social Instituyente. Zona Erógena. N 35, 1997.

CHATTERJEE, Partha. Colonialismo, Modernidade e Política. “A nação em tempo heterogêneo". Salvador: Edufba, 2004.

DALKILIÇ, Neslihan. "The Architectural analysis of traditional houses of Midyat Mardin, Turkey". International Journal of Academic Research Diyarbakir Vol.4, p.10-31, 2012.

DEVÉS-VALDÉS, Eduardo. Pensamiento Periférico: Asia - África - América Latina Eurasia y algo más. Una tesis interpretativa global. Santigo de Chile: Providencia, 2014.

ERDOGAN, Nezih. Narrative of resistance: Nacional identity and ambivalence in the Turkish melodrama between 1965 and 1975. Narratives of resistance, p. 259-271, 1998.

FEIERSTEIN, Daniel. El fin de la ilusión de autonomía. “Las contradicciones de la modernidad y su resolución genocida". In: AA.VV. Genocidio. La administración de la muerte en la modernidad. Buenos Aires: Eduntref, 2005.

FILIZ, Kardan. "The dynamics of honor killing in Turkey: Prospect for action" Ankara: United Nations Population Fund, 2005.

GINSBURG, Faye D. ABU-LUGHOD, Lila. LARKIN, Brian. et al. Media Worlds. Londres: Anthropology on New Terrain, 2002. 


\section{artigos}

A representação dos curdos no melodrama turco "Sila: prisioneira do amor" PÉREZ, Leonardo Cancino. Aportes de la noción de imaginario social para el estudio de los movimientos sociales. Polis Revista Latinoamericana, № 28. 2012.

SEZGIN, Dilara. WALL, Melissa A. Constructing the Kurds in the Turkish press: a case study of Hürriyet newspaper. Media culture and society, Vol.27, p.787-798, 2005.

HOLLANDA, Heloísa. B. Cultura como recurso. Salvador: Fundação Pedro Calmon. 2012.

HOBSBAWM, Eric. Nações e Nacionalismos desde 1780. Trad. Antônio Candido. Rio de Janeiro: Paz e terra,1991.

RANGER, Terence. A invenção das tradições. São Paulo: Paz e Terra, 2014. içLi, Tülin. G. Blood Feud In Turkey: A Sociological Analysis. The British Journal of Criminology, Vol 34, p. 69-74, 1994.

ÖCALAN, Abdullah. Guerra e paz no Curdistão. International Initiative Edition. 2008.

OCAKLI, Feryaz. Politics in the Kurdish periphery: clan networks and local party strategies in a comparative perspective. Middle Eastern Studies. Saratoga Springs, Vol. 53, p. 571-584, 2017.

MBEMBE, Achille. Necropolítica seguido de Sobre el gobierno privado indirecto. Trad. ARCHAMBAULT, Elisabeth. Editorial Melusina, S.L 2006.

VAN BRUINESSEN, Martin. Agha, Shaikh and State: The Social and Political Structures of Kurdistan. London: Zed Books, 1992.

'Kurdish identities and Kurdish nationalisms in the early twentyfirst century' Published in Turkish as: 'Erken 21. Yüzyılda Kürt Kimlikleri ve Kürt Milliyetçilikleri', in: Elçin Aktoprak \& A. Celil Kaya (eds), 21. Yüzyılda Milliyetçilik: Teori ve Siyaset. Istanbul: Iletişim, p. 1-16, 2016.

ZEYDANLIOGLU, Welat. The White Turkish Man's burden: Orientalism, Kemalism and the Kurds Turkey. In: RINGS, Guido; IFE, Anne (Eds.), Neo-colonial mentalities in contemporary Europe? Language and discourse in the construction of identities. London: Cambridge Scholars Publishing, p. 1-23, 2008 


\section{artigos}

Pricyla Weber Imaral

KILIÇBAY, Barış. INCIRLIOĞLU, Emine. O. Interrupted Happiness: Class Boundaries and the 'Impossible Love' in Turkish Melodrama.Ephemera reviews critical dialogues on organization, p. 236-249, 2003.

YÖRÜK, Zafer. Soft Power or Illusion of Hegemony: The Case of the Turkish Soap Opera "Colonialism". Izmir: University of Economics. International Journal of Communication, Vol.7, p. 2361-2385, 2013. 